\title{
Introduction to Part 2 of the Special Issue: Invited Papers from APAHC Award Honorees, 2013-2015
}

\author{
${\text { Elizabeth } \operatorname{Cash}^{1,2,3} \text { (D) Alisia G. T. T. Tran }}^{4}$
}

Published online: 1 March 2017

(C) Springer Science+Business Media New York 2017

This issue of the Journal of Clinical Psychology in Medical Settings (JCPMS) includes a continuation of the special issue highlighting the achievements and careers of seven distinguished psychologists whose work received special recognition during the time span of 2013-2015. They were chosen by the Awards Committee of the Association of Psychologists in Academic Health Centers (APAHC) to receive one of APAHC's achievement awards. The first installment of this special issue was published in December 2016. In that issue, we introduced the award recipients, described the inspiration for the special issue's format, presented the joint missions of both APAHC and JCPMS, and detailed the history of the awards (Cash \& Tran, 2016). We also provided information on the nature of each award, as well as the process of nomination, selection, and presentation for the APAHC awards.

This second section of the special issue rounds out the contributions of the APAHC award recipients from 2013 to 2015. The issue features both personal narratives and invited manuscripts highlighting our honorees' distinguished contributions to the field of psychology in academic medical settings. We hope that by showcasing such

Elizabeth Cash

liz.cash@louisville.edu

1 Department of Otolaryngology-Head \& Neck Surgery and Communicative Disorders, University of Louisville School of Medicine, Louisville, KY, USA

2 James Graham Brown Cancer Center, 529 S. Jackson Street, Louisville, KY 40202, USA

3 Department of Psychological and Brain Sciences, University of Louisville, Louisville, KY, USA

4 Counseling and Counseling Psychology, College of Integrative Sciences and Arts, Arizona State University, Tempe, AZ, USA influential psychologists, this special issue of JCPMS furthers the APAHC objective of advancing the science and practice of psychology and its role in academic health centers and beyond.

This special issue additionally affords an opportunity to place a spotlight on three new award categories introduced by the APAHC Awards Committee in November 2016. These new awards are designed to highlight outstanding contributions of psychologists early in their careers, thus representing a complement to the three existing award categories that recognize distinguished achievement during the full span of a career. The new awards commemorate student, early career, and mid-career psychologists' contributions.

\section{Outstanding Student Contributions Award}

Nominees for the Award for Outstanding Student Contributions to Psychology in Academic Health Centers should be exemplary graduate students or doctoral interns whose work in medical school and academic health care settings models the development of excellence in psychologists' roles in education, research, or clinical care.

\section{Outstanding Early Career Psychologist Contributions Award}

Nominees for the Award for Outstanding Early Career Psychologist Contributions to Psychology in Academic Health Centers should be exemplary post-doctoral fellows or psychologists less than 10 years post-degree whose work in medical school and academic health care settings has 
demonstrated excellence in psychologists' roles in education, research, or clinical care.

\section{Outstanding Mid-Career Psychologist Contributions Award}

Nominees for the Award for Outstanding Mid-Career Psychologist Contributions to Psychology in Academic Health Centers should be exemplary psychologists between 10 and 20 years post-degree whose work in medical school and academic health care settings has demonstrated excellence in enhancing psychologists' role in education, research, or clinical care.

The three preexisting APAHC achievement awards remain unchanged. They commemorate the work of psychologists who have made outstanding contributions during their careers in teaching, research, or to the advancement of psychology in academic health centers.

\section{Ivan Mensh Award for Distinguished Achievement in Teaching}

Nominees for the teaching award should be outstanding psychologists who work in and conduct innovative teaching and training in medical school and health care settings.

\section{Bud Orgel Award for Distinguished Achievement in Research}

Nominees for the research award should be outstanding psychologists who work in and contribute to the advancement of research and scholarship in medical school and health care settings.

\section{Joseph Matarazzo Award for Distinguished Contributions to Psychology in Academic Health Centers}

Nominees should be exceptional senior psychologists who have made substantial contributions to psychology in academic health centers across their careers.
Nominations for the 2017 APAHC achievement awards are under review by the APAHC Awards Committee. Those who are chosen will be announced at the March 2017 APAHC biennial meeting held in Detroit, Michigan. Regarding nominations for the 2019 APAHC awards, i.e., the next round of APAHC's biennial awards cycle, the call for nominations will be announced in late 2018.

The award nomination process is the same for all six awards, requiring that either current APAHC members, or recipients of a previous APAHC achievement award, make nominations to the APAHC Awards Committee. Non-APAHC members can be nominated for an APAHC achievement award. Nominations should include the name, curriculum vitae, and a 1-3 page letter of recommendation for the candidates; and prospective candidates should be notified of their nomination. The nominating statement should specify the nominee's achievements and contributions and provide other information in support of the nomination. The APAHC Awards Committee strongly encourages APAHC members to submit nominations to recognize their outstanding colleagues.

Compliance with Ethical Standards

Conflict of interest Elizabeth Cash and Alisia G.T.T. Tran declare that they have no conflict of interest.

Human and Animal Rights This article does not contain any studies with human participants or animals performed by the authors.

Informed Consent For this type of study, formal consent is not required.

\section{Reference}

Cash, E., \& Tran, A. G. T. T. (2016). Introduction to the special issue: Invited papers from APAHC award honorees, 2013-2015. Journal of Clinical Psychology in Medical Settings. doi:10.1007/ s10880-016-9476-5. 